\title{
Alternative Approaches for the Management of Diabetic Foot Ulcers
}

\section{Cassandra Pouget ${ }^{1}$, Catherine Dunyach-Remy ${ }^{2}$, Alix Pantel2, Adeline Boutet-Dubois², Sophie Schuldiner ${ }^{3}$, Albert Sotto ${ }^{4}$, Jean-Philippe Lavigne ${ }^{2 *}$ and Paul Loubet ${ }^{4}$}

\begin{abstract}
'Virulence Bactérienne et Infections Chroniques, INSERM U1047, Université de Montpellier, Nîmes, France, ${ }^{2}$ Virulence Bactérienne et Infections Chroniques, INSERM U1047, Université de Montpellier, Service de Microbiologie et Hygiène Hospitalière, Clinique du Pied Gard Occitanie, CHU Nimes, Nimes, France, ${ }^{3}$ Virulence Bactérienne et Infections Chroniques, INSERM U1047, Université de Montpellier, Service des Maladies Métaboliques et Endocriniennes, Clinique du Pied Gard Occitanie, CHU Nimes, Le Grau-du-Roi, France, ${ }^{4}$ Virulence Bactérienne et Infections Chroniques, INSERM U1047, Université de Montpellier, Service des Maladies Infectieuses et Tropicales, Clinique du Pied Gard Occitanie, CHU Nimes, Nimes, France
\end{abstract}

Diabetic foot ulcers (DFU) represent a growing public health problem. The emergence of multidrug-resistant (MDR) bacteria is a complication due to the difficulties in distinguishing between infection and colonization in DFU. Another problem lies in biofilm formation on the skin surface of DFU. Biofilm is an important pathophysiology step in DFU and may contribute to healing delays. Both MDR bacteria and biofilm producing microorganism create hostile conditions to antibiotic action that lead to chronicity of the wound, followed by infection and, in the worst scenario, lower limb amputation. In this context, alternative approaches to antibiotics for the management of DFU would be very welcome. In this review, we discuss current knowledge on biofilm in DFU and we focus on some new alternative solutions for the management of these wounds, such as antibiofilm approaches that could prevent the establishment of microbial biofilms and wound chronicity. These innovative therapeutic strategies could replace or complement the classical strategy for the management of DFU to improve the healing process.

Keywords: alternative therapeutic approaches, biofilm, chronic wound, diabetic foot, antibiofilm

\section{INTRODUCTION}

Diabetic foot ulcers (DFU) have a lifetime prevalence of 15-25\% (Armstrong et al., 2017). Infection is the most common, severe and costly (Prompers et al., 2008) DFU complication with high risk of mortality and morbidity associated with lower limb amputation (Bakker et al., 2016). The diagnosis of diabetic foot infection (DFI) is often difficult, leading to the inappropriate use of antibiotics. The bacterial organization in DFU and the involvement of multidrug-resistant (MDR) bacteria require new antimicrobial solutions. This review discusses the role of the biofilm in DFU and alternative approaches to classical treatment that could improve DFU management.

Abbreviations: AMP, antimicrobial peptide; c-di-GMP, cyclic diguanylate; C2DA, cis-2-decenoic acid; DFI, diabetic foot infection; DFP, deferiprone; DFU, diabetic foot ulcer; DNA, deoxyribonucleic acid; DMSO, dimethyl sulfoxide; EDTA, ethylene diamine tetra-acetic; EGTA, egtazic acid; EPS, extracellular polymeric substance; FEP, functionally equivalent pathogroups; MDR, multidrug resistance; MRSA, methicillin-resistant Staphylococcus aureus; MSC, mesenchymal stem cells; NGAD, next generation antibiofilm carboxymethyl cellulose silver containing wound dressing; QS, quorum sensing. 


\section{Clinical and Translational Relevance}

Sixty to $80 \%$ of chronic wounds harbor bacterial structures in a biofilm (James et al., 2008; Malone et al., 2017a). For the clinician, the main difficulty is to distinguish between infecting and colonizing bacteria. Misclassification can lead to inappropriate antibiotic prescriptions that contribute to promoting the emergence of MDR bacteria, a major DFU health issue (Caravaggi et al., 2013). Better understanding of the bacterial organization of biofilms in chronic wounds would allow development of tailored antimicrobial strategies and improving wound healing. In this context, a large majority of current fundamental studies on DFUs focuses on bacterial cooperation and the impact of local microenvironment on microorganisms. Thus, the host-microorganism interface plays a major role in DFI development. In DFU, bacteria are classically organized in functionally equivalent pathogroups (FEP) where pathogenic and commensal bacteria co-aggregate symbiotically in a pathogenic biofilm to maintain a chronic infection (Dowd et al., 2008). Polymicrobial biofilms have been observed both in pre-clinical studies using animal models and in clinical research on DFU. They represent the main cause of healing delay. Recently, some approaches have targeted biofilm formation with the aim of controlling infections (Snyder et al., 2017). Better understanding of the host-bacterial interactions is essential to develop new therapeutic solutions that take into account the biofilm to limit the diffusion of MDR bacteria.

\section{Diabetic Foot Ulcers and Biofilms}

Biofilm formation is a multistep process (see for review Percival et al., 2015) whereby heterogeneous communities of microorganisms (bacteria and/or fungi) are embedded into an extracellular polymeric substance (EPS) matrix that contains proteins, deoxyribonucleic acid (DNA), glycoproteins and polysaccharides, and confers the ability to adhere to biotic or abiotic surfaces (Bjarnsholt, 2013). In DFU, the biofilm architectural structure differs among patients due to the variability of the involved bacterial genera and species. Conversely, the multistep formation process is similar. Biofilm formation is a major mechanism of adaptation that protects bacteria from antibiotics, due to several characteristics (Singh et al., 2017). Biofilm structure provides a protective layer against antimicrobial compounds. Wounds biofilms are polymicrobial, formed by complex and order combinations of microorganisms. Hence, compounds produced by different bacterial strains might impair the contact between the bacterial cell wall and the antibiotic by changing the composition of the EPS. Finally, the production of degradative enzymes by different pathogens can act in synergy against antibiotics. These biofilm aspects are responsible for a reduced diffusion of the antibiotic within the biofilm matrix leading to an inefficient activity of the antibiotic treatment (Sharma et al., 2019). In addition to this feature, the ability to form a biofilm is an effective strategy to enhance survival and persistence of microorganisms by increasing their antimicrobial resistance. The antimicrobial resistance in organisms producing biofilms acts by delayed penetration of the antimicrobial agents through the biofilm matrix, altered growth rate of biofilm organisms, and other physiological changes due to the biofilm mode of growth (Donlan and Costerton, 2002).

\section{CLASSICAL STRATEGIES IN THE MANAGEMENT OF DIABETIC FOOT ULCERS}

The management of patients with a DFU is a multidisciplinary approach that includes all relevant specialties (i.e., nursing, orthopedics, plastic surgery, vascular surgery, nutrition, infectious diseases, microbiology, and endocrinology departments) (Cahn et al., 2014). To aid the clinician during the management of DFUs, classification of stage and severity of the wound must be established (Lipsky et al., 2020). The classical care for the control and treatment of DFUs is centered on perfusion, pressure moderation, control of the infection, control of the glycaemic balance, foot discharge and debridement (Wu et al., 2007) (Table 1).

\section{Debridement of the Wound}

Debridement consists in the removal of necrotic, devitalized and/or infected tissue from a wound, leaving healthy tissue preserved. Surgical debridement is the usual method used. The objective is to control the bacterial load, which, in combination with antimicrobial treatment, allows early closure of the wound (Wolcott et al., 2009). Debridement enables the wound and surrounding tissues to promote normal healing by removing infected tissues, biofilms, and senescent cells. Debridement allows the reepithelialization of soft-tissue by eradication of (early or established) infection and reduction of bioburden, the improvement of local blood flow, and the revitalization of the wound bed. When it was performed correctly, it optimizes the diabetic wound healing.

\section{Negative Pressure Wound Therapy}

Associated with debridement, negative pressure wound therapy is an airtight open-pore placed onto the wound and covered by an airtight dressing. Then, the wound is connected to a vacuum source and a negative pressure is generated. The negative pressure at the wound site reduces the size of the wound through contraction; it continuously cleans the wound by removing small debris through suction and reduces levels of proteases through wound fluid removal (Apelqvist et al., 2017). The efficiency of this therapy has been confirmed and it represents an effective measure of promoting wound healing, although the evidence is low (Liu et al., 2018).

\section{Antimicrobial Therapy for Infected Diabetic Foot Ulcers}

Antibiotics are not used to manage colonized DFU (Lipsky et al., 2020). Their use concerned the different stages of DFI. Antibiotics are mainly empirical in the first instance, in accordance with the causative pathogen and the severity of the infection. The definitive antibiotic treatment is changed according to the microbiological culture and the response of the 
TABLE 1 | In vitro and in vivo effects of the main alternative approaches studied.

\begin{tabular}{|c|c|c|c|}
\hline & In vitro effects & In vivo effects & References \\
\hline \multicolumn{4}{|l|}{ Debridement } \\
\hline Negative pressure therapy & - & Enhance wound closure & Apelqvist et al., 2017; Liu et al., 2018 \\
\hline \multicolumn{4}{|l|}{ Antimicrobial agents } \\
\hline $\begin{array}{l}\text { Calcium sulfate beads with } \\
\text { antibiotics }\end{array}$ & Decreased viability of MRSA strains & No clinical evaluation & Price et al., 2016 \\
\hline Nanoparticles & $\begin{array}{l}\text { Silver nanoparticles affect } P \text {. aeruginosa biofilm } \\
\text { formation }\end{array}$ & No clinical evaluation & $\begin{array}{l}\text { Beyth et al., 2015; Ahmadi and } \\
\text { Adibhesami, 2017; Hamdan et al., 2017; } \\
\text { Mihai et al., } 2018\end{array}$ \\
\hline Oxyclozanide & $\begin{array}{l}\text { Enhances aminoglycoside and tetracycline killing in } \\
\text { S. aureus biofilms }\end{array}$ & No clinical evaluation & Maiden et al., 2019 \\
\hline Guanylated polymethacrylates & $\begin{array}{l}\text { Effective killing of } C \text {. albicans and } S \text {. aureus in } \\
\text { polymicrobial biofilms }\end{array}$ & Untested in human DFU & Qu et al., 2016 \\
\hline Guar gum-associated nisin & $\begin{array}{l}\text { Reduction of biofilm formation by S. aureus isolates } \\
\text { from patients }\end{array}$ & Evaluation with strains isolated from DFI & $\begin{array}{l}\text { I Cirioni et al., 2006; Dutta and Das, 2016; } \\
\text { Santos et al., 2016; Thombare et al., } 2016\end{array}$ \\
\hline Acapsil & - & $\begin{array}{l}\text { Shorter hospital stay and faster wound } \\
\text { healing }\end{array}$ & Bilyayeva et al., 2017 \\
\hline
\end{tabular}

\section{Antiseptics}

Cadexomer iodine

Nutraceuticals

Cranberry

Tannic acid

Tea-tree oil and Cinnamon oil Effect on MRSA biofilm

Ellagic acid

Propolis and honey

Probiotics

Phage therapy
Limits S. aureus biofilm formation and enhances antibiotic susceptibility

Anti-inflammatory and anti-bacterial properties

Lactobacilli antibiofilm activity

Reduction of biofilm formation and infection by $P$. aeruginosa, $S$. aureus, and $A$. baumannii

\section{Action on wound healing}

\section{Photodynamic therapy}

Hyperbaric oxygen therapy

Non-thermal plasma

Electrostimulation

Alternatives for inhibition of adhesion and biofilm

Inhibition of initial bacterial adhesion

EDTA and citrate

Aryl rhodanines

\section{Interaction with biofilm metabolism by QS stimulus modulation}

Furanone

Sodium ascorbate
Prevention of biofilm formation and degradation of pre-existing biofilm (via $\mathrm{Mg}^{2+}, \mathrm{Ca}^{2+}$, and iron chelators)

Inhibition of biofilm formation by S. aureus and other Gram-positive bacteria by targeting early stage of adhesion

Inhibition of biofilm formation and expression of $P$. aeruginosa virulence factors

Modulation of QS signal in $P$. aeruginosa
Reduction $(1 \log 10)$ of microbial load and biofilm in DFU (11/17 patients)
Schwartz et al., 2013; Malone et al., 2017b

Decrease of Escherichia coli, S. aureus LaPlante et al., 2012 adhesion

Acceleration of cutaneous wound healing in rat model

Payne et al., 2013; Orlowski et al., 2018; Chen et al., 2019

Reduction of the quantity of colonized Kwieciński et al., 2009; Lee et al., 2014; MRSA and promotion of healing of Cui et al., 2016; Seyed Ahmadi et al., 2019 chronic wounds in a clinical trial

No clinical evaluation

Quave et al., 2012

Reduction of bacterial load of chronic Henshaw et al., 2014; Jull et al., 2015; wounds in combination with antibiotics Martinotti and Ranzato, 2015;

Minden-Birkenmaier and Bowlin, 2018;

McLoone et al., 2020

Acceleration of wound healing in mice Vuotto et al., 2014; Vågesjö et al., 2018

Reduction of bacterial load and wound Mendes et al., 2014; Fish et al., 2018; Hill closure in diabetic mouse wound et al., 2018; Morozova et al., 2018; Taha infections

et al., 2018; Albac et al., 2020; Kifelew et al., 2020

Increase of reepithelization

Tardivo et al., 2014

Improvement of short-term healing Kranke et al., 2015

Acceleration of wound healing in animal Chatraie et al., 2018; Cooley et al., 2020 models of ulcers

Evaluation with dressings

Barki et al., 2019

Raad et al., 2008

Prevention of infection in a rabbit catheter model (with minocycline)

No clinical evaluation

Opperman et al., 2009

Decrease of $P$. aeruginosa virulence

Kim et al., 2012; García-Contreras et al., 2013

No clinical evaluation

El-Mowafy et al., 2014 
TABLE 1 | (Continued)

\begin{tabular}{|c|c|c|c|}
\hline & In vitro effects & In vivo effects & References \\
\hline Savarin & $\begin{array}{l}\text { Inhibition of S. aureus biofilm formation (by } \\
\text { targeting agr) }\end{array}$ & No clinical evaluation & Sully et al., 2014 \\
\hline Azithromycin & $\begin{array}{l}\text { Inhibition of biofilm formation and expression of } \\
P . \text { aeruginosa virulence factors }\end{array}$ & $\begin{array}{l}\text { Improvement of clinical signs in patients } \\
\text { with CF and } P \text {. aeruginosa infections }\end{array}$ & Bala et al., 2011 \\
\hline RNAll inhibiting peptide & Reduction of $S$. aureus virulence & $\begin{array}{l}\text { Healing improvement in a chronic } \\
\text { wound mouse model }\end{array}$ & Giacometti et al., 2003 \\
\hline c-di-GMP & $\begin{array}{l}\text { Reduction of biofilm formation in } P \text {. aeruginosa } \\
\text { and } A \text {. baumannii }\end{array}$ & No clinical evaluation & $\begin{array}{l}\text { Romling et al., 2013; Lieberman et al., } \\
\text { 2014; Wu et al., } 2015\end{array}$ \\
\hline Exo-polysaccharides & $\begin{array}{l}\text { Reduction of biofilm formation ( } P \text {. aeruginosa) } \\
\text { by targeting virulence factors + PA01 and } \\
\text { S. epidermidis in co-culture }\end{array}$ & No clinical evaluation & $\begin{array}{l}\text { Pihl et al., 2010; Jiang et al., 2011; } \\
\text { Rendueles et al., 2013; Limoli et al., } 2015\end{array}$ \\
\hline 1,018-peptide and derivates & $\begin{array}{l}\text { Disruption of } P \text {. aeruginosa and } B \text {. cenocepacia } \\
\text { mature biofilms }\end{array}$ & No clinical evaluation & $\begin{array}{l}\text { Willcox et al., 2008; de la Fuente-Núñez } \\
\text { et al., 2012, } 2014\end{array}$ \\
\hline Deferiprone & $\begin{array}{l}\text { Activity against coagulase-negative } \\
\text { staphylococci }\end{array}$ & No clinical evaluation & Coraça-Huber et al., 2018 \\
\hline \multicolumn{4}{|c|}{ Enzymes enhancing bacterial dispersion } \\
\hline$\alpha$-amylase & Disruption of biofilm formed by S. aureus & No clinical evaluation & Kalpana et al., 2012 \\
\hline$\alpha$-amylase and cellulase & Disruption of biofilm & $\begin{array}{l}\text { In vivo disruption but the dispersal can } \\
\text { cause systemic infection }\end{array}$ & Fleming et al., 2017 \\
\hline DNase, dispersin B & Eradication of single and multi-species biofilms & No clinical evaluation & $\begin{array}{l}\text { Chen and Lee, 2018; Sharma and Pagedar } \\
\text { Singh, } 2018\end{array}$ \\
\hline 2-aminoimidazole & Disruption of biofilms formed by $S$. aureus & No clinical evaluation & Rogers et al., 2010 \\
\hline Lysostaphin & Eradication of $P$. aeruginosa biofilms & $\begin{array}{l}\text { Effective treatment for biofilm disruption } \\
\text { on jugular vein catheters in mice }\end{array}$ & Kokai-Kun et al., 2009 \\
\hline C2DA & $\begin{array}{l}\text { Dispersion of S. aureus, Action on MRSA } \\
\text { biofilm }\end{array}$ & No clinical evaluation & Jennings et al., 2012 \\
\hline \multicolumn{4}{|c|}{ Next-generation dressings and grafts } \\
\hline $\begin{array}{l}\text { NGAD NGAD + mesenchymal } \\
\text { stem cells }\end{array}$ & $\begin{array}{l}\text { Removal of biofilms by } S \text {. aureus and } \\
\text { antibiotic-resistant } P \text {. aeruginosa }\end{array}$ & Evaluation with clinical strains & $\begin{array}{l}\text { Parsons et al., 2016; Pérez-Díaz et al., } \\
\text { 2018; Tarusha et al., } 2018\end{array}$ \\
\hline Electrospun nanofibers & $\begin{array}{l}\text { Prevent biofilm formation and enhance } \\
\text { fibroblast development }\end{array}$ & No clinical evaluation & Ramalingam et al., 2019 \\
\hline Surfactant based gel & - & $\begin{array}{l}\text { Reduced bacteria development and } \\
\text { biofilm infection }\end{array}$ & Yang et al., 2017; Percival et al., 2018 \\
\hline $\begin{array}{l}\text { Dehydrated amniotic } \\
\text { membranes }\end{array}$ & $\begin{array}{l}\text { Faster wound healing in patients with severe } \\
\text { comorbidities }\end{array}$ & Lower extremity wounds & Lullove, 2017 \\
\hline Sucrose octasulfate & - & $\begin{array}{l}\text { Significant increase of wound closure } \\
\text { rate }\end{array}$ & Edmonds et al., 2018 \\
\hline Skin substitutes & - & $\begin{array}{l}\text { Fish skin offers natural } \\
\text { anti-inflammatory properties and } \\
\text { promotes growth of new skin. Other } \\
\text { wounds and patients with burns }\end{array}$ & See clinicaltrials.gov NCT01348581 \\
\hline Arenicola marina & $\begin{array}{l}\text { This new dressing delivers oxygen to the wound } \\
\text { bed, enhancing healing and cell proliferation }\end{array}$ & No evaluation clinical & Le Pape et al., 2018 \\
\hline Epigel ${ }^{\circledR}$ & $\begin{array}{l}\text { This new bioactive hydrogel hydrates the } \\
\text { wound bed }\end{array}$ & No clinical evaluation & See www.epinovabiotech.com \\
\hline $\begin{array}{l}\text { Keratinocyte treatment. Skin } \\
\text { grafts (epithelial or fetal cells). } \\
\text { Stem cells. Collagen I matrix. } \\
\text { Human placental tissues. }\end{array}$ & - & Improve closure time & $\begin{array}{l}\text { Kanji and Das, 2017; Lo et al., 2019; } \\
\text { Lintzeris et al., 2018; Mao et al., 2018; } \\
\text { Momeni et al., 2019; Hassanshahi et al., } \\
\text { 2019; Hwang et al., 2019; Oropallo, } 2019\end{array}$ \\
\hline 3D-printed scaffolds & - & Shorter healing time & $\begin{array}{l}\text { Pushparaj and Ranganathan, 2017; Sun } \\
\text { et al., } 2018\end{array}$ \\
\hline
\end{tabular}

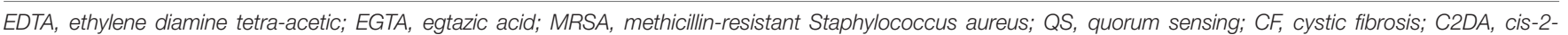
decenoic acid; DFI, diabetic foot infection; DFU, diabetic foot ulcer; NGAD, next-generation carboxymethylcellulose silver- containing wound dressing.

empirical treatment (Kwon and Armstrong, 2018). Its duration will depend on the severity of the infection. However, Walker et al. (2015) reported that $74 \%$ of DFUs did not respond to topical and systemic agents. Recently, Johani et al. (2018) confirmed this observation. Uçkay et al. (2018) could not demonstrate a beneficial effect of topical therapy using gentamicin-sponges in 88 DFUs. Similar conclusions were drawn for vancomycin powder, although infections were more superficial in patients 
treated with vancomycin than in controls (untreated) (Wukich et al., 2015). A recent Cochrane review on this topic indicated that randomized controlled data on the effectiveness and safety of topical antimicrobial for DFI are limited (Dumville et al., 2017).

As bacteria in biofilms display 100 to 1,000 -fold higher tolerance to antibiotics, new solutions to deliver antibiotics at high concentration into the biofilm have been developed. Delivery systems could be used to administer high concentrations of antibiotics to the wound with limited side effects. Biodegradable vehicles, such as calcium sulfate beads, display a good elution profile and seem to be compatible with many antibiotics. Natural polymers, such as collagen sponges, are another emerging delivery system, although data are still limited for DFU (Markakis et al., 2018). For instance, calcium sulfate beads are mineral elements that are naturally absorbed into biofilms and then slowly dissolve to release antibiotics. Price et al. (2016) showed in vitro that calcium sulfate beads loaded with gentamicin or tobramycin eradicated Pseudomonas aeruginosa biofilms in DFU, and also reduced the viability of MRSA strains. The main problem of this approach is the potential risk of bacterial resistance selection. Randomized trials are required to confirm the efficacy of these approaches.

Recently, Maiden et al. (2019) showed that the ionophore oxyclozanide can enhance aminoglycoside and tetracycline killing activity in $P$. aeruginosa biofilms by reducing the bacterial cell membrane potential and increasing antibiotic accumulation within the biofilm. Currently, this compound is mainly used in veterinary medicine for parasitic infections, but this finding suggests that in combination with aminoglycosides, oxyclozanide could represent a new antibiofilm agent for chronic wound treatment.

\section{ALTERNATIVE APPROACHES IN THE MANAGEMENT OF DIABETIC FOOT ULCERS}

In addition to conventional approaches, new alternative solutions have emerged in recent years, targeting the bacterial organization and notably the biofilm formation of DFU (Table 1).

\section{Antimicrobial Peptides and Related Drugs}

Santos et al. (2016) reported that nisin, a bacteriocin against Gram-positive bacteria, was active against some Gram-negative bacteria. Nisin promotes the disintegration of the bacterial cell membrane lipid bilayer by electrostatic interactions. Its use in DFU requires an effective delivery system. An in vitro study showed that guar gum-associated nisin reduced biofilm formation by $23 \mathrm{~S}$. aureus strains isolated from DFU, including MDR strains (Thombare et al., 2016). Similarly, citropin is active against $P$. aeruginosa and $S$. aureus without major toxicity in animal models (Cirioni et al., 2006). However, Dutta and Das (2016) highlighted the limitations of antimicrobial peptides (AMPs), especially in terms of production costs, bioavailability, and difficult clinical translation.
Guanylated polymethacrylates are a new class of antimicrobial agents that structurally mimics AMPs and efficiently kills both fungi and bacteria in polymicrobial biofilms (Candida albicans and S. aureus) (Qu et al., 2016). A study on 266 patients with venous leg ulcers and DFU showed that, compared with gentaxane and iodine/dimethyl sulfoxide (DMSO), Acapsil ${ }^{\circledR}$ (Willingsford Healthcare), a powder based on a micropore particle technology, accelerated wound healing and reduced hospitalization length (Bilyayeva et al., 2017).

\section{Nanotechnologies}

Nanotechnology-based therapies open the door to new therapeutic solutions for chronic wounds (Hamdan et al., 2017). Nanoparticles made of iron, silver, zinc, or titanium showed antibacterial activity (disruption of the bacterial membrane) (Beyth et al., 2015), and due to their high bioavailability, they can penetrate into mature biofilms and target sessile bacteria. Therefore, these materials could be used to target both surface bacteria and biofilm-organized bacteria in deeper tissues. A recent study showed that the combination of silver nanoparticles and tetracycline reduced the bacterial load and promoted healing in wounds inoculated with $P$. aeruginosa in mice (Ahmadi and Adibhesami, 2017). A recent review has summarized nanotechnology-based wound healing approaches and their benefits (Mihai et al., 2018).

\section{Antiseptics}

Topical antiseptics are antimicrobial agents that inhibit or reduce the number of microorganisms. Unlike antibiotics, antiseptics have multiple targets and a broader spectrum of activity including bacteria, fungi, viruses, or protozoa. They have commonly been used on wounds to prevent or treat infection; however, antiseptic fluid irrigation have received little scientific study and their efficiency remain questioned (Lipsky et al., 2020). Indeed, wound cleansers may affect normal human cells and may be antimitotic affecting normal tissue repair. Repeated and excessive treatment of wounds with antiseptics without proper indications may have negative outcomes or promote a microenvironment similar to those found in chronic wounds. With the discovery of polymicrobial biofilms and the emergence of bacteria tolerant to antiseptics, their effectiveness is even more questionable (Sheldon, 2005; Ortega Morente et al., 2013; Stewart, 2015). Following these observations, international guidelines suggest that antiseptics are not appropriate in the management of DFU (Lipsky et al., 2020).

However, some recent studies present interesting results. Products, such as Octenilin ${ }^{\circledR}$ (Schülke \& Mayr GmbH), iodine-based solutions, polyhexamethylene biguanide or silverimpregnated dressings, are good in vitro candidates (KucisecTepes, 2016; Pavlik et al., 2019) to reduce biofilms, but their effectiveness against polymicrobial and complex biofilms remains to be demonstrated (Khan and Naqvi, 2006). Similarly, chlorhexidine action is clearly limited on multi-species biofilms (Touzel et al., 2016). Townsend et al. (2016) developed a new in vitro inter-kingdom wound biofilm model on hydrogel-based cellulose to test the efficacy of common topical antiseptics. They treated biofilms composed of C. albicans, P. aeruginosa, and 
S. aureus with chlorhexidine or povidone iodine, and found that the structure of polymicrobial biofilms was only slightly affected compared with that of monomicrobial biofilms. They also showed that topical antiseptics were less efficient against polymicrobial biofilms.

Cadexomer iodine is a topical antimicrobial agent that could be used to deliver iodine into wounds. Iodine can penetrate the pathogen cell wall and disrupt proteins, as well as the nucleic acid structure and synthesis. Cadexomer iodine can be encapsulated within small polysaccharide beads that, in the presence of the wound exudate, start to swell and release iodine into the wound. In vivo studies have demonstrated that cadexomer iodine significantly reduced biofilm and microbial load in DFU (Schwartz et al., 2013; Malone et al., 2017b).

\section{Nutraceuticals}

Nutraceuticals are pharmaceutical alternatives that include all foods or food products which provide medical benefits and can be delivered under medical form. These products could present health benefits, and several plant-derived natural compounds could prove clinically beneficial.

A study has reported that cranberry extracts inhibited biofilm production of Gram-positive bacteria (LaPlante et al., 2012). Polyphenolic compounds, such as tannic acid (Orlowski et al., 2018; Chen et al., 2019 in a rats model) and tea-tree oil (Lee et al., 2014 in a clinical trial), also inhibited biofilm formation by $S$. aureus, including methicillin-resistant $S$. aureus (MRSA) (Kwieciński et al., 2009), by cleaving peptidoglycan (Payne et al., 2013). An active compound found in cinnamon oil has also been shown to prevent MRSA biofilm formation in vitro (Cui et al., 2016), and also in a mice model of wound infection (Seyed Ahmadi et al., 2019). Finally, ellagic acid derivatives also limited S. aureus biofilm formation and enhanced its susceptibility to some antibiotics (Quave et al., 2012). All these compounds must be clinically evaluated in chronic wounds.

The natural anti-inflammatory and antimicrobial properties of propolis produced by honeybees are well known. Its regenerative properties and low cost explain the increased interest in propolis for promoting chronic wound healing (Henshaw et al., 2014; Martinotti and Ranzato, 2015). To our knowledge, propolis alone has not been used in DFU, but a recent review summarized the effect of propolis with a combination of several antibiotics in skin problems including wounds (McLoone et al., 2020).

Honey has been used for a long time to treat wounds with no real proof of its efficiency. A study demonstrated that in animals, honey has a clear antibacterial effect, but no anti-inflammatory activity (Jull et al., 2015). Recently, Minden-Birkenmaier and Bowlin (2018) reviewed the effects of different types of honey on wound closure and antibiofilm activity. They also discussed the advantages of honey in the field of tissue engineering and biomaterials (Cryogels, Electrospun templates, and Hydrogels).

Within a biofilm, intra- and inter-species interactions and cooperation can be observed at the different stages of its formation. Another approach could be to harness the bacterial competition to modify the dispersion or modification of the growing matrix. Probiotic bacteria, such as Lactobacilli, could have antibiofilm activities and be good candidates for wound treatment (Vuotto et al., 2014; Vågesjö et al., 2018 in in vivo model).

\section{Phage Therapy}

There is renewed interest in bacteriophages to fight bacteria. In this treatment, viruses infect a specific bacterium and reproduce inside it. Several areas must be investigated to evaluate the potential of bacteriophages in the therapeutic arsenal (Knezevic et al., 2021). Indeed, the success of phage therapy is highly dependent on the efficiency and safety of phage preparations, which raises manufacturing and formulation challenges. The production of phages must comply with the strict regulations that are usually applied for pharmaceutical products to ensure the high-quality standards appropriate for their intended. This needs a production with a controlled and reproducible process. One of the requirements is to avoid phages encoding for lysogeny, virulence factors or antibiotic resistance. The presence of impurities such as endotoxins in phage preparations should also be avoided or be below a threshold. The presence/absence of neutralizing antibodies binding against phages must be known. The development of "phagogram" (in parallel to antibiogram) could be also an important way for the routine use of phage therapy. However, this could represent another approach for the treatment of infected wounds with minimal effects on the host microbiome (Hill et al., 2018; Morozova et al., 2018). Mendes et al. (2014) tested an in vitro cocktail of bacteriophages targeting S. aureus, $P$. aeruginosa, and Acinetobacter baumannii on both planktonic cells and biofilm-associated cells, and found that it reduced biofilm formation and infection. Other case reports have described encouraging results in patients with diabetic foot and chronic wounds (Fish et al., 2018; Taha et al., 2018).

To date, one of the main limitations is that the evaluation of phage efficiency has been performed using mainly in vitro studies and a single species in a biofilm. However, biofilms in DFU are multi-species, impacting the spatial organization and the interaction with phages. The specific outcome of phage infection in a multi-species biofilm seems to strongly depend on the bacterial species composing the biofilm (e.g., whether they establish synergist or antagonist interactions). The complexity of phage-biofilm interactions is increased by evidence of biofilm formation induced by exposure to certain phages (Lacqua et al., 2006; Tan et al., 2015; Henriksen et al., 2019). Overall, even if the potential of phages to control the complex biofilm observed in DFU is proved, the complexity and diversity of phagebiofilm interactions could limit broad conclusions and need more research to claim that phage therapy becomes a real solution in the DFU situation.

\section{Therapeutic Solutions on Wound Healing}

Photodynamic therapy could be an interesting approach to aid wound healing. In this therapeutic procedure, pathogen cell death is induced upon exposure to light to generate oxygen species by activation of a photosensitizing agent. This agent is non-toxic in the dark, but after illumination, it becomes a very efficient antimicrobial agent. This method is used mainly in oncology, but it could also be employed to manage chronic wounds notably by its ability to prevent amputation in diabetic patients with 
DFU. Indeed, a clinical study showed that all non-treated patients ( $n=16)$ underwent amputation, compared to only one patient in the group that received photodynamic therapy $(n=18)$ (Tardivo et al., 2014).

Another technology uses non-thermal plasma. Here, plasma is a partially ionized medium composed of many elements, such as charged particles (electrons and ions), neutral and excited atoms, UV photons and radicals. A recent study in rats showed that this technology could be used on pressure ulcers to accelerate wound healing (Chatraie et al., 2018). Additional investigations are needed to determine its value in humans, but recent results using an in vivo mouse model of type 2 diabetes showed promotion of bacterial killing of $P$. aeruginosa and wound disinfection without metabolic complication (Cooley et al., 2020).

Application of electrical stimulation has also been investigated in wound repair and regeneration. Wireless electroceutical dressings were recently tested in a porcine chronic wound polymicrobial biofilm infection model with $P$. aeruginosa (PAO1) and A. baumannii (19606) (Barki et al., 2019). The data suggested that the dressing disrupted wound biofilm aggregates and accelerated wound closure by restoring skin barrier function. The dressing changed expression of $P$. aeruginosa quorum sensing $m v f R(p q s R), r h l R$, and lasR genes and silencing of E-cadherin (a protein required for skin barrier function). Finally, this study highlighted the rescue effect against biofilm-induced persistent inflammation by decreased cytokines production.

Finally, hyperbaric oxygen therapy had been used for several years in the management of DFU. It consists in inhalation of pure oxygen after entering a special compression chamber. The treatment aims to increase the oxygen supply to the wound. However, the value of this therapy is controversial and its effect seems more due to the foot discharge than the oxygen itself. In a Cochrane review, the authors concluded that the therapy improved short-term but not long-term healing in patients with DFUs (Kranke et al., 2015).

\section{Alternatives in the Inhibition of Bacterial Adhesion and Biofilm Inhibition of Initial Bacterial Adhesion}

Bacterial growth requires the presence of metals (particularly, calcium, iron, and magnesium). Ionic chelators could be used to limit bacterial growth and initial adhesion. Ethylene diamine tetra-acetic (EDTA) and citrate are the most promising compounds of this class (Raad et al., 2008). However, the efficiency of these chelators is dependent on the bacterial strains. For instance, Abraham et al. (2012) observed that the antibiofilm effect varied among $S$. aureus isolates. Aryl rhodanines also can inhibit the early stages of biofilm development by preventing the attachment on the surface of $S$. aureus and other Gram-positive bacteria, but not of Gram-negative bacteria (Opperman et al., 2009).

\section{Inhibiting Biofilm Metabolism}

Quorum Sensing (QS) is important for the transition from antimicrobial-sensitive planktonic cells to antimicrobial-resistant cell aggregates in a biofilm. In the absence of QS signal, biofilm formation is inhibited. Many researchers have evaluated compounds to modulate QS, such as furanone that inhibited, among others, $P$. aeruginosa biofilms (Kim et al., 2012), sodium ascorbate that modulated the QS signal in $P$. aeruginosa (ElMowafy et al., 2014), savarin (a S. aureus virulence inhibitor) (Sully et al., 2014), and azithromycin in P. aeruginosa (Bala et al., 2011). Moreover, RNA III inhibiting peptide reduced $S$. aureus and Staphylococcus epidermidis virulence and improved healing in rats (Giacometti et al., 2003). These approaches are efficient only on a restricted number of bacterial species, and due to their potential toxicity, they have a limited use. Moreover, it has been reported that some bacteria isolated from clinical samples have become resistant to some QS modulators (García-Contreras et al., 2013), suggesting the emergence of multi-QS inhibitor resistant bacteria (Koul et al., 2016).

Another approach uses the cyclic diguanylate inhibition. Cyclic diguanylate (c-di-GMP) is a second messenger that controls many cellular functions, including biofilm formation. Various stress factors, such as starvation, reduced c-di-GMP level, leading to biofilm dispersal (Romling et al., 2013). This study also found that dispersed cells were more virulent compared with the first planktonic cells that induced the biofilm and with biofilm sessile cells. Moreover, small molecules, such as LP 3134, LP 3145, LP 4010, and LP 1062, inhibited a key enzyme that mediated c-di-GMP synthesis and consequently also biofilm formation in P. aeruginosa and A. baumannii (Wu et al., 2015). Unfortunately, these molecules seem to be toxic to eukaryotic cells. Finally, ebselen inhibited c-di-GMP and displayed good results on $P$. aeruginosa biofilms (Lieberman et al., 2014).

The biofilm matrix mainly contains proteins, extracellular DNA and polysaccharides. Polysaccharides are important for the early stage of biofilm formation and can protect cells during biofilm maturation. They also provide the basal biofilm structure that allows the bacterial community stratification. A recent study demonstrated that the exo-polysaccharide EPS273, obtained from a marine bacterium, reduced biofilm formation in $P$. aeruginosa by targeting virulence factors (Jiang et al., 2011). Other antibiofilm polysaccharides have been discovered, for instance Psl and Pel from P. aeruginosa PAO1 that decreased $S$. epidermidis biofilm formation in a co-culture biofilm in vivo model (Pihl et al., 2010). Other non-bacterial polysaccharides from animals, plants and algae have also shown antibiofilm activity (Rendueles et al., 2013).

In stress conditions, bacteria synthesize alarmones (guanosine tetraphosphate and guanosine pentaphosphate) called (p)ppGpp (Willcox et al., 2008). The antibiofilm peptide 1,018 inhibited their accumulation upon nutritional stress and prevented biofilm formation. Moreover, at low concentration, it eradicated biofilmassociated bacteria and disrupted mature biofilms. This peptide and its derivatives HE4 and HE10 were similarly effective against $P$. aeruginosa and Burkholderia cenocepacia biofilms (de la Fuente-Núñez et al., 2014). In addition, peptide 1,037 reduced biofilms formed by other bacteria (the Gram-negative pathogens $P$. aeruginosa and $B$. cenocepacia, and the Gram-positive Listeria monocytogenes) (de la Fuente-Núñez et al., 2012).

Finally, a recent study showed that the iron chelator deferiprone (DFP) affected bacterial biofilm formation and had synergistic effects (antibacterial activity) with some antibiotic 
compounds against coagulase-negative staphylococci. The potential of DFP is clearly based on its potentiation of the antibiotics action, leading to a significant biofilm reduction (Coraça-Huber et al., 2018).

\section{Promoting Bacterial Dispersion}

One promising therapeutic approach consists in targeting the EPS matrix with dispersing agents in combination with antibiotics. For instance, the $\alpha$-amylase (Kalpana et al., 2012; Fleming et al., 2017) enzyme, which is produced by marine bacteria, can disrupt polysaccharide bonds. It is now used as a dispersing agent to target the polysaccharide bonds of the EPS matrix, leading to biofilm degradation in vitro. Other enzymes (deoxyribonuclease I, the hydrolases dispersin B and DNase) also showed EPS matrix-degrading properties (Fleming et al., 2017; Chen and Lee, 2018; Sharma and Pagedar Singh, 2018).

Some synthetic agents have been developed, such as 2aminoimidazole for S. aureus biofilms (Rogers et al., 2010) and synthetic lysostaphin, an effective treatment for established biofilm infections on implanted jugular vein catheters in mice (Kokai-Kun et al., 2009).

In addition, the enzymes proteinase $\mathrm{K}$ and trypsin can eradicate biofilms from a variety of staphylococcal strains on inert surfaces. However, their efficacy for the elimination of established biofilms is not well known in vivo, thus limiting their therapeutic potential. Moreover, this strategy might lead to the release of bacteria from the biofilm into the blood circulation that could induce a strong inflammatory response or a systemic acute infection.

Cis-2-Decenoic acid (C2DA) is a fatty acid chemical messenger produced by $P$. aeruginosa that induces the dispersion of biofilms with $S$. aureus and other Gram-positive and Gramnegative bacteria (Davies and Marques, 2009). C2DA controls the initiation of biofilm formation and the dispersion of mature biofilms. C2DA can inhibit MRSA biofilm formation/growth, but cannot eradicate them (Jennings et al., 2012).

\section{New Generation of Dressing and Grafts}

Parsons et al. (2016) developed a next-generation antibiofilm carboxymethylcellulose silver-containing wound dressing (NGAD). This hydrofiber dressing was designed to disperse the wound biofilm and to enhance ionic silver antimicrobial action. The authors showed that NGAD was more efficient (biofilm disruption and removal) than other commercial dressings in a large panel of clinical isolates, including $S$. aureus and antibiotic-resistant $P$. aeruginosa. Another in vitro study conducted on a novel wound-dressing material based on a matrix of the polysaccharides alginate, hyaluronic acid and Chitlac-silver nanoparticles concluded that hyaluronic acid was able to stimulate the wound healing simultaneously to the silver particles allowing efficient antibacterial activity against biofilms (Tarusha et al., 2018). Pérez-Díaz et al. (2018) combined these nanoparticles with mesenchymal stem cells (MSC) that can improve wound healing due to their ability to differentiate and release growth factors. In addition to the MSC and nanoparticles, they used radiosterilized pig skin as a matrix to deliver MSC into wound beds. In vitro data suggested a decrease of bacterial growth and biofilm formation. Finally, Ramalingam et al. (2019) conducted a study presenting the utility of electrospun nanofiber containing a natural extract (Gymnema sylvestre) that prevented biofilm formation, inhibited both Gram-positive and Gram-negative bacteria, and enhanced human dermal fibroblasts development in an in vitro model.

A surfactant-based wound gel dressing described in a porcine skin explant infected with $P$. aeruginosa (PAO1) biofilm showed encouraging results. Dressing the wound with this gel reduced bacteria development and biofilm infection (Yang et al., 2017). More recently, Percival et al. (2018) highlighted the effects of a non-ionic surfactant, the Pluronic F127 used in combination with melatonin and chitosan in a wound dressing. The microspheres of Pluronic F127 enhanced chitosan properties allowing antimicrobial and antibiofilm activity against $S$. aureus (Percival et al., 2018).

A dehydrated amniotic membrane allograft was used in 22 patients with lower extremity wounds (Lullove, 2017). At week 12 after application of the human amniotic membrane, DFU were completely healed.

A randomized double-blind clinical trial showed that sucrose octasulfate significantly improves wound closure in neuroischemic DFU after 20 weeks of treatment (Edmonds et al., 2018).

Skin substitutes could be another therapeutic solution in wound healing. The Food and Drug Administration recently approved a treatment for wound care involving fish skin after a clinical trial to determine its effectiveness on burns and different wound types. Fish skin contains omega-3 fatty acids that have natural anti-inflammatory properties and can accelerate healing. An ongoing clinical trial is evaluating an extracellular matrix that binds to the cells around the wound and promotes the growth of new skin (see clinicaltrials.gov/NCT01348581).

Arenicola marina is a technology based on the finding that lack of oxygen in chronic wounds hampers healing and cell proliferation (Le Pape et al., 2018). HEMHealing ${ }^{\circledR}$ (Hemarine) provides oxygenation to the wound by including M101 hemoglobin in the dressing matrix. M101 hemoglobin is an oxygen carrier that belongs to the extra-cellular hemoglobin family and is found in the Arenicola marina marine worm. This hemoglobin can naturally fix oxygen from the external environment and then gradually release it in the hypoxic medium to restart the healing process. In a wound context, it could restart cell proliferation and decrease wound budding.

Skin works as an extracellular matrix that binds to the cells around the wound and promotes the growth of new skin. Epigel ${ }^{\circledR}$ (Epinova Biotech) is an innovative patch based on a highly hydrophilic, biocompatible and bioactive hydrogel scaffold that supports wound bed hydration, thus reducing healing time. Clinical trials must be done to evaluate the value of Epigel ${ }^{\circledR}$ as wound dressing.

Hwang et al. (2019) evaluated allogeneic keratinocyte grafts (weekly grafts for up to 12 weeks) in 71 patients with intractable DFUs. They reported wound healing in $78.8 \%$ of patients: $64.7 \%$ with complete healing within an average of 6.1 weeks, and $14.1 \%$ with partial healing and an average $35.5 \%$ reduction of the initial size at the end of the follow up. This treatment seems effective for 
chronic and difficult-to-treat DFUs. In line with other studies [in fetal cells (Momeni et al., 2019) or epithelial cells (Lo et al., 2019)] in other wound types, this study showed the benefit of skin grafts that could represent the future management of chronic wounds. Indeed, progenitor stem cells present in these grafts can accelerate wound repair and tissue regeneration, and consequently decrease the risk of wound infection. A significant number of stem cell therapies for cutaneous wounds are currently under development (Kanji and Das, 2017).

Chronic wounds are inflammatory processes that result in the increase of proteolytic enzymes and degradation of the extracellular matrix. Two studies investigated the impact of providing a biocompatible scaffold to support the healing. They used a purified Type I collagen matrix containing polyhexamethylene biguanide on patients $(n=8$ and $n=41)$ suffering from DFU. Their results suggested that the collagen matrix improved both wound closure and the wound bed condition (Lintzeris et al., 2018; Oropallo, 2019). Finally, a study investigated the effect of human placental tissues against P. aeruginosa and S. aureus biofilm (Mao et al., 2018). It highlighted the fact that both human cryopreserved viable amniotic membrane and cryopreserved viable umbilical tissue had antibacterial activity against multiple bacterial pathogens and demonstrated that these tissues released factors that inhibited biofilm formation of $P$. aeruginosa and $S$. aureus in an ex vivo porcine model. Recently, use of adipose-derived stem cell improved wound healing by promoting angiogenesis and/or vascularization, modulating immune response, and inducing epithelialization in the wound (Hassanshahi et al., 2019).

The effectiveness of 3D-printed scaffolds in chronic wounds has not yet been proven, but this seems to be a promising strategy. Sun et al. (2018) reported that 3D-printed scaffold membrane alone ( $n=1$ patient), and 3D-printed scaffold powder mixed with platelet-rich fibrinogen $(n=2)$ reduced healing time in patients with pressure ulcer and/or DFU (Sun et al., 2018). Another group developed a 3D-printed scaffold that included a drug delivery system based on the body temperature (Pushparaj and Ranganathan, 2017). Although this device has not been tested in vivo yet, it is the first step toward the use of $3 \mathrm{D}$-printed

\section{REFERENCES}

Abraham, N. M., Lamlertthon, S., Fowler, V. G., and Jefferson, K. K. (2012). Chelating agents exert distinct effects on biofilm formation in Staphylococcus aureus depending on strain background: role for clumping factor B. J. Med. Microbiol. 61, 1062-1070. doi: 10.1099/jmm.0.040758-0

Ahmadi, M., and Adibhesami, M. (2017). The effect of silver nanoparticles on wounds contaminated with Pseudomonas aeruginosa in mice: an experimental study. Iran. J. Pharm. Res. 16, 661-669.

Albac, S., Medina, M., Labrousse, D., Hayez, D., Bonnot, D., Anzala, N., et al. (2020). Efficacy of bacteriophages in a Staphylococcus aureus nondiabetic or diabetic foot infection murine model. Antimicrob. Agents Chemother. 64, e01870-19. doi: 10.1128/AAC.01870-19

Apelqvist, J., Willy, C., Fagerdahl, A. M., Fraccalvieri, M., Malmsjö, M., Piaggesi, A., et al. (2017). Negative pressure wound therapy - overview, challenges and perspectives. J. Wound Care. 26:3. doi: 10.12968/jowc.2017.26.Sup3.S1

Armstrong, D. G., Boulton, A. J. M., and Bus, S. A. (2017). Diabetic Foot Ulcers and Their Recurrence. N. Engl. J. Med. 376, 2367-2375. doi: 10.1056/ NEJMra1615439 scaffolds that incorporate the delivery of drugs (antibiotics or antibiofilm molecules) to shorten healing time and decrease the risks of infection and complication.

\section{CONCLUSION}

The severity of DFU and the difficulty in treating it has prompted researchers to take a closer look at these infections and the associated issues. Biofilms play a crucial role in DFUs and contribute to delay healing. Research now must take into account the biofilm bacterial organization in these chronic wounds in order to identify novel alternative therapeutic candidates to improve DFU management. As we described above, alternative strategies such as bacteriophages, probiotics, AMPs or antibiofilms are exciting strategies and show promising results. All these compounds could provide solutions against MDR bacteria. However, additional studies are required to understand the biofilm bacterial organization in DFU, and also the mechanisms behind each of the candidates to improve the wound healing management and thus offer new therapeutic solution for the management of DFU.

\section{AUTHOR CONTRIBUTIONS}

CP, PL, J-PL, and AS wrote the manuscript. CD-R, AP, AB-D, and $\mathrm{SS}$ critically reviewed the manuscript. All authors contributed to the article and approved the submitted version.

\section{ACKNOWLEDGMENTS}

AP, CD-R, AS, PL, and J-PL belong to the FHU INCh (Federation Hospitalo Universitaire Infections Chroniques, Aviesan). We thank the Nîmes University Hospital for its structural, human and financial support through the award obtained by our team during the internal call for tenders "Thématiques phares". We thank Sarah Kabani for her editing assistance.

Bakker, K., Apelqvist, J., Lipsky, B. A., Van Netten, J. J., and International Working Group on the Diabetic Foot. (2016). The 2015 IWGDF guidance documents on prevention and management of foot problems in diabetes: development of an evidence-based global consensus. Diabetes Metab. Res. Rev. 32, 2-6. doi: 10.1002/dmrr.2694

Bala, A., Kumar, R., and Harjai, K. (2011). Inhibition of quorum sensing in Pseudomonas aeruginosa by azithromycin and its effectiveness in urinary tract infections. J. Med. Microbiol. 60, 300-306. doi: 10.1099/jmm.0.025387-0

Barki, K. G., Das, A., Dixith, S., Ghatak, P. D., Mathew-Steiner, S., Schwab, E., et al. (2019). Electric Field Based Dressing Disrupts Mixed-Species Bacterial Biofilm Infection and Restores Functional Wound Healing. Ann. Surg. 269, 756-766. doi: 10.1097/SLA.0000000000002504

Beyth, N., Houri-Haddad, Y., Domb, A., Khan, W., and Hazan, R. (2015). Alternative antimicrobial approach: nano-antimicrobial materials. Evid. Based Complement. Alternat. Med. 2015:246012. doi: 10.1155/2015/246012

Bilyayeva, O. O., Neshta, V. V., Golub, A. A., and Sams-Dodd, F. (2017). Comparative clinical study of the wound healing effects of a novel micropore particle technology: effects on wounds, venous leg ulcers, and diabetic foot ulcers. Wounds 29, 1-9. 
Bjarnsholt, T. (2013). The role of bacterial biofilms in chronic infections. APMIS 136, 1-51. doi: 10.1111/apm.12099

Cahn, A., Elishuv, O., and Olshtain-Pops, K. (2014). Establishing a multidisciplinary diabetic foot team in a large tertiary hospital: a workshop. Diabetes Metab. Res. Rev. 30, 350-353. doi: 10.1002/dmrr.2527

Caravaggi, C., Sganzaroli, A., Galenda, P., Bassetti, M., Ferraresi, R., and Gabrielli, L. (2013). The management of the infected diabetic foot. Curr. Diabetes Rev. 9, $7-24$.

Chatraie, M., Torkaman, G., Khani, M., Salehi, H., and Shokri, B. (2018). In vivo study of non-invasive effects of non-thermal plasma in pressure ulcer treatment. Sci. Rep. 8:5621. doi: 10.1038/s41598-018-24049-z

Chen, K. J., and Lee, C. K. (2018). Twofold enhanced dispersin B activity by $\mathrm{N}$-terminal fusion to silver-binding peptide for biofilm eradication. Int. J. Biol. Macromol. 118, 419-426. doi: 10.1016/j.ijbiomac.2018.06.066

Chen, Y., Tian, L., Yang, F., Tong, W., Jia, R., Zou, Y., et al. (2019). Tannic Acid Accelerates Cutaneous Wound Healing in Rats Via Activation of the ERK 1/2 Signaling Pathways. Adv Wound Care 8, 341-354. doi: 10.1089/wound.2018. 0853

Cirioni, O., Giacometti, A., Ghiselli, R., Kamysz, W., Orlando, F., Mocchegiani, F., et al. (2006). Citropin 1.1-treated central venous catheters improve the efficacy of hydrophobic antibiotics in the treatment of experimental staphylococcal catheter-related infection. Peptides 27, 1210-1216. doi: 10.1016/j.peptides.2005. 10.007

Cooley, C. R., McLain, J. M., Dupuy, S. D., Eder, A. E., Wintenberg, M., Kelly-Wintenberg, K., et al. (2020). Indirect, Non-Thermal Atmospheric Plasma Promotes Bacterial Killing in vitro and Wound Disinfection in vivo Using Monogenic and Polygenic Models of Type 2 Diabetes (Without Adverse Metabolic Complications). Shock 54, 681-687. doi: 10.1097/SHK. 0000000000001583

Coraça-Huber, D. C., Dichtl, S., Steixner, S., Nogler, M., and Weiss, G. (2018). Iron chelation destabilizes bacterial biofilms and potentiates the antimicrobial activity of antibiotics against coagulase-negative Staphylococci. Pathog. Dis. 76. doi: 10.1093/femspd/fty052

Cui, H., Li, W., Li, C., Vittayapadung, S., and Lin, L. (2016). Liposome containing cinnamon oil with antibacterial activity against methicillin-resistant Staphylococcus aureus biofilm. Biofouling 32, 215-225. doi: 10.1080/08927014. 2015.1134516

Davies, D. G., and Marques, C. N. (2009). A fatty acid messenger is responsible for inducing dispersion in microbial biofilms. J. Bacteriol. 191, 1393-1403. doi: 10.1128/JB.01214-08

de la Fuente-Núñez, C., Korolik, V., Bains, M., Nguyen, U., Breidenstein, E. B. M., Horsman, S., et al. (2012). Inhibition of bacterial biofilm formation and swarming motility by a small synthetic cationic peptide. Antimicrob. Agents Chemother. 56, 2696-2704. doi: 10.1128/AAC.00064-12

de la Fuente-Núñez, C., Mansour, S., Wang, Z., Jiang, L., Breidenstein, E. B. M., Eliott, M., et al. (2014). Anti-biofilm and immunomodulatory activities of peptides that inhibit biofilms formed by pathogens isolated from cystic fibrosis patients. Antibiotics 3, 509-526. doi: 10.3390/antibiotics3040509

Donlan, R. M., and Costerton, J. W. (2002). Biofilms: survival mechanisms of clinically relevant microorganisms. Clin. Microbiol. Rev. 15, 167-193. doi: 10. 1128/cmr.15.2.167-193.2002

Dowd, S. E., Wolcott, R. D., Sun, Y., McKeehan, T., Smith, E., and Rhoads, D. (2008). Polymicrobial nature of chronic diabetic foot ulcer biofilm infections determined using bacterial tag encoded FLX amplicon pyrosequencing (bTEFAP). PLoS One 3:e3326. doi: 10.1371/journal.pone.000 3326

Dumville, J. C., Lipsky, B. A., Hoey, C., Cruciani, M., Fiscon, M., and Xia, J. (2017). Topical antimicrobial agents for treating foot ulcers in people with diabetes. Cochrane Database Syst. Rev. 6:CD011038. doi: 10.1002/14651858.CD011038. pub2

Dutta, P., and Das, S. (2016). Mammalian antimicrobial peptides: promising therapeutic targets against infection and chronic inflammation. Curr. Top. Med. Chem. 16, 99-129. doi: 10.2174/1568026615666150703121819

Edmonds, M., Lázaro-Martínez, J. L., Alfayate-García, J. M., Martini, J., Petit, J. M., Rayman, G., et al. (2018). Sucrose octasulfate dressing versus control dressing in patients with neuroischaemic diabetic foot ulcers (Explorer): an international, multicentre, double-blind, randomised, controlled trial. Lancet Diabetes Endocrinol. 6, 186-196. doi: 10.1016/S2213-8587(17)30438-2
El-Mowafy, S. A., Shaaban, M. I., and Abd El Galil, K. H. (2014). Sodium ascorbate as a quorum sensing inhibitor of Pseudomonas aeruginosa. J. Appl. Microbiol. 117, 1388-1399. doi: 10.1111/jam.12631

Fish, R., Kutter, E., Bryan, D., Wheat, G., and Kuhi, S. (2018). Resolving digital staphylococcal osteomyelitis using bacteriophage-A case report. Antibiotics 7:87. doi: $10.3390 /$ antibiotics7040087

Fleming, D., Chahin, L., and Rumbaugh, K. (2017). Glycoside hydrolases degrade polymicrobial bacterial biofilms in wounds. Antimicrob. Agents Chemother. 61, e01998-16. doi: 10.1128/AAC.01998-16

García-Contreras, R., Martínez-Vázquez, M., Velázquez Guadarrama, N., Villegas Pañeda, A. G., Hashimoto, T., Maeda, T., et al. (2013). Resistance to the quorum-quenching compounds brominated furanone C-30 and 5-fluorouracil in Pseudomonas aeruginosa clinical isolates. Pathog. Dis. 68, 8-11. doi: 10.1111/ 2049-632X.12039

Giacometti, A., Cirioni, O., Gov, Y., Ghiselli, R., Del Prete, M. S., Mocchegiani, F., et al. (2003). RNA III inhibiting peptide inhibits in vivo biofilm formation by drug-resistant Staphylococcus aureus. Antimicrob. Agents Chemother. 47, 1979-1983. doi: 10.1128/AAC.47.6.1979-1983.2003

Hamdan, S., Pastar, I., Drakulich, S., Dikici, E., Tomic-Canic, M., Deo, S., et al. (2017). Nanotechnology-driven therapeutic interventions in wound healing: potential uses and applications. ACS Cent. Sci. 3, 163-175. doi: 10.1021/ acscentsci.6b00371

Hassanshahi, A., Hassanshahi, M., Khabbazi, S., Hosseini-Khah, Z., Peymanfar, Y., Ghalamkari, S., et al. (2019). Adipose-derived stem cells for wound healing. J. Cell Physiol. 234, 7903-7914. doi: 10.1002/jcp.27922

Henriksen, K., Rørbo, N., Rybtke, M. L., Martinet, M. G., Tolker-Nielsen, T., Høiby, N., et al. (2019). P. aeruginosa flow-cell biofilms are enhanced by repeated phage treatments but can be eradicated by phage-ciprofloxacin combination. Pathog. Dis. 77:ftz011. doi: 10.1093/femspd/ftz011

Henshaw, F. R., Bolton, T., Nube, V., Hood, A., Veidhoen, D., Pfrunder, L., et al. (2014). Topical application of the bee hive protectant propolis is well tolerated and improves human diabetic foot ulcer healing in a prospective feasibility study. J. Diabetes Complications 28, 850-857. doi: 10.1016/j.jdiacomp.2014. 07.012

Hill, C., Mills, S., and Ross, R. P. (2018). Phages \& antibiotic resistance: are the most abundant entities on earth ready for a comeback? Future Microbiol. 13, 711-726. doi: 10.2217/fmb-2017-0261

Hwang, Y. G., Lee, J. W., Park, K. H., and Han, S. H. (2019). Allogeneic keratinocyte for intractable chronic diabetic foot ulcers: a prospective observational study. Int. Wound J. 16, 486-491. doi: 10.1111/iwj.13061

James, G. A., Swogger, E., Wolcott, R., Pulcini, Secor, P., Sestrich, J., et al. (eds) (2008). Biofilms in chronic wounds. Wound Repair. Regen. 16, 37-44. doi: 10.1111/j.1524-475X.2007.00321.x

Jennings, J. A., Courtney, H. S., and Haggard, W. O. (2012). Cis-2-decenoic acid inhibits S. aureus growth and biofilm in vitro: a pilot study. Clin. Orthop. Relat. Res. 470, 2663-2670. doi: 10.1007/s11999-012-2388-2

Jiang, P., Li, J., Han, F., Duan, G., Lu, X., Gu, Y., et al. (2011). Antibiofilm activity of an exopolysaccharide from marine bacterium Vibrio sp. QY101. PLoS One 6:e18514. doi: 10.1371/journal.pone.0018514

Johani, K., Malone, M., Jensen, S. O., Dickson, H. G., Gosbell, I. B., Hu, H., et al. (2018). Evaluation of short exposure times of antimicrobial wound solutions against microbial biofilms: from in vitro to in vivo. J. Antimicrob. Chemother. 73, 494-502. doi: 10.1093/jac/dkx391

Jull, A. B., Cullum, N., Dumville, J. C., Westby, M. J., Deshpande, S., and Walker, N. (2015). Honey as a topical treatment for wounds. Cochrane Database Syst. Rev. 3:CD005083. doi: 10.1002/14651858.CD005083.pub4

Kalpana, B. J., Aarthy, S., and Pandian, S. K. (2012). Antibiofilm activity of $\alpha-$ amylase from Bacillus subtilis S8-18 against biofilm forming human bacterial pathogens. Appl. Biochem. Biotechnol. 167, 1778-1794. doi: 10.1007/s12010011-9526-2

Kanji, S., and Das, H. (2017). Advances of stem cell therapeutics in cutaneous wound healing and regeneration. Mediators Inflamm. 2017:5217967. doi: 10. $1155 / 2017 / 5217967$

Khan, M. N., and Naqvi, A. H. (2006). Antiseptics, iodine, povidone iodine and traumatic wound cleansing. J. Tissue Viability 16, 6-10. doi: 10.1016/s0965206x(06)64002-3

Kifelew, L. G., Warner, M. S., Morales, S., Vaughan, L., Woodman, R., Fitridge, R., et al. (2020). Efficacy of phage cocktail AB-SA01 therapy in diabetic mouse 
wound infections caused by multidrug-resistant Staphylococcus aureus. BMC Microbiol. 20:204. doi: 10.1186/s12866-020-01891-8

Kim, S. G., Yoon, Y. H., Choi, J. W., Rha, K. S., and Park, Y. H. (2012). Effect of furanone on experimentally induced Pseudomonas aeruginosa biofilm formation: in vitro study. Int. J. Pediatr. Otorhinolaryngol. 76, 1575-1578. doi: 10.1016/j.ijporl.2012.07.015

Knezevic, P., Hoyle, N. S., Matsuzaki, S., and Gorski, A. (2021). Advances in phage therapy: present challenges and future perspectives. Front. Microbiol. 12:701898. doi: 10.3389/fmicb.2021.701898

Kokai-Kun, J. F., Chanturiya, T., and Mond, J. J. (2009). Lysostaphin eradicates established Staphylococcus aureus biofilms in jugular vein catheterized mice. J. Antimicrob. Chemother. 64, 94-100. doi: 10.1093/jac/dkp145

Koul, S., Prakash, J., Mishra, A., and Kalia, V. C. (2016). Potential Emergence of Multi-quorum Sensing Inhibitor Resistant (MQSIR) Bacteria. Indian J. Microbiol. 56, 1-18. doi: 10.1007/s12088-015-0558-0

Kranke, P., Bennett, M. H., Martyn-St James, M., Schnabel, A., Debus, S. E., and Weibel, S. (2015). Hyperbaric oxygen therapy for chronic wounds. Cochrane Database Syst. Rev. 2015:CD004123. doi: 10.1002/14651858.CD004123.pub4

Kucisec-Tepes, N. (2016). [The role of antiseptics and strategy of biofilm removal in chronic wound]. Acta Med. Croat. 70, 33-42.

Kwieciński, J., Eick, S., and Wójcik, K. (2009). Effects of tea tree (Melaleuca alternifolia) oil on Staphylococcus aureus in biofilms and stationary growth phase. Int. J. Antimicrob. Agents 33, 343-347. doi: 10.1016/j.ijantimicag.2008. 08.028

Kwon, K. T., and Armstrong, D. G. (2018). Microbiology and Antimicrobial Therapy for Diabetic Foot Infections. Infect. Chemother. 50, 11-20. doi: 10. 3947/ic.2018.50.1.11

Lacqua, A., Wanner, O., Colangelo, T., Martinotti, M. G., and Landini, P. (2006). Emergence of biofilm-forming subpopulations upon exposure of Escherichia coli to environmental bacteriophages. Appl. Environ. Microbiol. 72, 956-959. doi: 10.1128/AEM.72.1.956-959.2006

LaPlante, K. L., Sarkisian, S. A., Woodmansee, S., Rowley, D. C., and Seeram, N. P. (2012). Effects of cranberry extracts on growth and biofilm production of Escherichia coli and Staphylococcus species. Phyther. Res. 26, 1371-1374. doi: 10.1002/ptr.4592

Le Pape, F., Richard, G., Porchet, E., Sourice, S., Dubrana, F., Férec, C., et al. (2018). Adhesion, proliferation and osteogenic differentiation of human MSCs cultured under perfusion with a marine oxygen carrier on an allogenic bone substitute. Artif. Cells Nanomed. Biotechnol. 46, 95-107. doi: 10.1080/21691401. 2017.1365724

Lee, R. L. P., Leung, P. H. M., and Wong, T. K. S. (2014). A randomized controlled trial of topical tea tree preparation for MRSA colonized wounds. Int. J. Nursing Sci. 1, 7-14. doi: 10.1016/j.ijnss.2014.01.001

Lieberman, O. J., Orr, M. W., Wang, Y., and Lee, V. T. (2014). High-Throughput screening using the differential radial capillary action of ligand assay identifies Ebselen as an inhibitor of diguanylate cyclases. ACS Chem. Biol. 9, 183-192. doi: $10.1021 / \mathrm{cb} 400485 \mathrm{k}$

Limoli, D. H., Jones, C. J., and Wozniak, D. J. (2015). Bacterial extracellular polysaccharides in biofilm formation and function. Microbiol. Spectr. 3, 10.1128/microbiolspec.MB-0011-2014.doi: 10.1128/microbiolspec.MB-00112014

Lintzeris, D., Vernon, K., Percise, H., Strickland, A., Yarrow, K., White, A., et al. (2018). Effect of a New Purified Collagen Matrix With Polyhexamethylene Biguanide on Recalcitrant Wounds of Various Etiologies: a Case Series. Wounds $30,72-78$.

Lipsky, B. A., Senneville, E., Abbas, Z. G., Aragón-Sánchez, J., Diggle, M., Embil, J. M., et al. (2020). Guidelines on the diagnosis and treatment of foot infection in persons with diabetes (IWGDF 2019 update). Diabetes Metab. Res. Rev. 36:e3280. doi: 10.1002/dmrr.3280

Liu, Z., Dumville, J. C., Hinchliffe, R. J., Cullum, N., Game, F., Stubbs, N., et al. (2018). Negative pressure wound therapy for treating foot wounds in people with diabetes mellitus. Cochrane Database Syst. Rev. 10:CD010318. doi: 10.1002/ 14651858.CD010318.pub3

Lo, C. H., Akbarzadeh, S., McLean, C., Ives, A., Paul, E., Brown, W. A., et al. (2019). Wound healing after cultured epithelial autografting in patients with massive burn injury: a cohort study. J. Plast. Reconstr. Aesthet. Surg. 72, 427-437. doi: 10.1016/j.bjps.2018.11.003
Lullove, E. J. (2017). Use of a dehydrated amniotic membrane allograft in the treatment of lower extremity wounds: a retrospective cohort study. Wounds 29, 346-351.

Maiden, M. M., Zachos, M. P., and Waters, C. M. (2019). The ionophore oxyclozanide enhances tobramycin killing of Pseudomonas aeruginosa biofilms by permeabilizing cells and depolarizing the membrane potential. J. Antimicrob. Chemother. 74, 894-906. doi: 10.1093/jac/dky545

Malone, M., Bjarnsholt, T., McBain, A. J., James, G. A., Stoodley, P., Leaper, D., et al. (2017a). The prevalence of biofilms in chronic wounds: a systematic review and meta-analysis of published data. J. Wound Care 26, 20-25. doi: 10.12968/jowc.2017.26.1.20

Malone, M., Johani, K., Jensen, S. O., Gosbell, I. B., Dickson, H. G., McLennan, S., et al. (2017b). Effect of cadexomer iodine on the microbial load and diversity of chronic non-healing diabetic foot ulcers complicated by biofilm in vivo. J. Antimicrob. Chemother. 72, 2093-2101. doi: 10.1093/jac/dkx099

Mao, Y., Sharma-Varma, A., Hoffman, T., Dhall, S., Danikovitch, A., Kohn, J., et al. (2018). The Effect of Cryopreserved Human Placental Tissues on Biofilm Formation of Wound-Associated Pathogens. J. Funct. Biomater. 9:3. doi: 10. 3390/jfb9010003

Markakis, K., Faris, A. R., Sharaf, H., Faris, B., Rees, S., and Bowling, F. L. (2018). Local antibiotic delivery systems: current and future applications for diabetic foot infections. Int. J. Low Extrem. Wounds 17, 14-21. doi: 10.1177/ 1534734618757532

Martinotti, S., and Ranzato, E. (2015). Propolis: a new frontier for wound healing? Burns Trauma 3, 9. doi: 10.1186/s41038-015-0010-z

McLoone, P., Tabys, D., and Fyfe, L. (2020). Honey Combination Therapies for Skin and Wound Infections: a Systematic Review of the Literature. Clin. Cosmet. Investig. Dermatol. 13, 875-888. doi: 10.2147/CCID.S282143

Mendes, J. J., Leandro, C., Mottola, C., Barbosa, R., Silva, F. A., Oliveira, M., et al. (2014). In vitro design of a novel lytic bacteriophage cocktail with therapeutic potential against organisms causing diabetic foot infections. J. Med. Microbiol. 63, 1055-1065. doi: 10.1099/jmm.0.071753-0

Mihai, M. M., Preda, M., Lungu, J., Gestal, M. C., Popa, M. I., and Holban, A. M. (2018). Nanocoatings for Chonic wound repair modulation of microbial colonization and biofilm formation. Int. J. Mol. Sci. 19:1179. doi: 10.3390/ ijms19041179

Minden-Birkenmaier, B., and Bowlin, G. (2018). Honey-based templates in Wound healing and tissue engineering. Bioengineering 5:46. doi: 10.3390/ bioengineering 5020046

Momeni, M., Fallah, N., Bajouri, A., Bagheri, T., Orouji, Z., Pahlevanpour, P., et al. (2019). A randomized, double-blind, phase I clinical trial of fetal cell-based skin substitutes on healing of donor sites in burn patients. Burns 45, 914-922. doi: 10.1016/j.burns.2018.10.016

Morozova, V. V., Vlassov, V. V., and Tikunova, N. V. (2018). Applications of bacteriophages in the treatment of localized infections in humans. Front. Microbiol. 9:1696. doi: 10.3389/fmicb.2018.01696

Opperman, T. J., Kwasny, S. M., Williams, J. D., Khan, A. R., Peet, N. P., Moir, D. T., et al. (2009). Aryl rhodanines specifically inhibit staphylococcal and enterococcal biofilm formation. Antimicrob. Agents Chemother. 53, 4357-4367. doi: 10.1128/AAC.00077-09

Orlowski, P., Zmigrodzka, M., Tomaszewska, E., Ranoszek-Soliwoda, K., Czupryn, M., Antos-Bielska, M., et al. (2018). Tannic acid-modified silver nanoparticles for wound healing: the importance of size. Int. J. Nanomed. 13, 991-1007. doi: 10.2147/IJN.S154797

Oropallo, A. R. (2019). Use of Native Type I Collagen Matrix Plus Polyhexamethylene Biguanide for Chronic Wound Treatment. Plast. Reconstr. Surg. Glob. Open 7:e2047. doi: 10.1097/GOX.0000000000002047

Ortega Morente, E., Fernández-Fuentes, M. A., Grande Burgos, M. J., Abriouel, H., Pérez Pulido, R., and Gálvez, A. (2013). Biocide tolerance in bacteria. Int. J. Food Microbiol. 162, 13-25. doi: 10.1016/j.ijfoodmicro.2012.12.028

Parsons, D., Meredith, K., Rowlands, V. J., Short, D., Metcalf, D. G., and Bowler, P. G. (2016). Enhanced performance and mode of action of a novel antibiofilm hydrofiber ${ }^{\circledR}$ wound dressing. Biomed. Res. Int. 2016:7616471. doi: 10.1155/ 2016/7616471

Pavlik, V., Sojka, M., Mazúrová, M., and Velebnÿ, V. (2019). Dual role of iodine, silver, chlorhexidine and octenidine as antimicrobial and antiprotease agents. PLoS One 14:e211055. doi: 10.1371/journal.pone.0211055 
Payne, D. E., Martin, N. R., Parzych, K. R., Rickard, A. H., Underwood, A., and Boles, B. R. (2013). Tannic acid inhibits Staphylococcus aureus surface colonization in an IsaA-dependent manner. Infect. Immun. 81, 496-504. doi: 10.1128/IAI.00877-12

Percival, S. L., Chen, R., Mayer, D., and Salisbury, A. M. (2018). Mode of action of poloxamer-based surfactants in wound care and efficacy on biofilms. Int. Wound J. 15, 749-755. doi: 10.1111/iwj.12922

Percival, S. L., McCarty, S. M., and Lipsky, B. (2015). Biofilms and Wounds: an Overview of the Evidence. Adv. Wound Care 4, 373-381. doi: 10.1089/wound. 2014.0557

Pérez-Díaz, M. A., Silva-Bermudez, P., Jiménez-López, B., Martínez-López, V., Melgarejo-Ramire, Y., Brena-Molina, A., et al. (2018). Silver-pig skin nanocomposites and mesenchymal stem cells: suitable antibiofilm cellular dressings for wound healing. J. Nanobiotechnol. 16:2. doi: 10.1186/s12951-0170331-0

Pihl, M., Davies, J. R., Chávez de Paz, L. E., and Svensäter, G. (2010). Differential effects of Pseudomonas aeruginosa on biofilm formation by different strains of Staphylococcus epidermidis. FEMS Immunol. Med. Microbiol. 59, 439-446. doi: 10.1111/j.1574-695X.2010.00697.x

Price, B. L., Lovering, A. M., Bowling, F. L., and Dobson, C. B. (2016). Development of a novel collagen wound model to simulate the activity and distribution of antimicrobials in soft tissue during diabetic foot infection. Antimicrob. Agents Chemother. 60, 6880-6889. doi: 10.1128/AAC.01064-16

Prompers, L., Schaper, N., Apelqvist, J., Edmonds, M., Jude, E., Mauricio, D., et al. (2008). Prediction of outcome in individuals with diabetic foot ulcers: focus on the differences between individuals with and without peripheral arterial disease. Eurodiale Study. Diabetol. 51, 747-755. doi: 10.1007/s00125-008-0940-0

Pushparaj, M., and Ranganathan, R. (2017). Application of 3D printing in electroinduced drug delivery based on wound temperature. Int. Res. J. Pharm. 8, 179-183. doi: 10.7897/2230-8407.0811238

Qu, Y., Locock, K., Verma-Gaur, J., Hay, I. D., Meagher, L., and Traven, A. (2016). Searching for new strategies against polymicrobial biofilm infections: guanylated polymethacrylates kill mixed fungal/bacterial biofilms. J. Antimicrob. Chemother. 71, 413-421. doi: 10.1093/jac/dkv334

Quave, C. L., Estévez-Carmona, M., Compadre, C. M., Hobby, G., Hendrickson, H., Beenken, K. E., et al. (2012). Ellagic acid derivatives from Rubus ulmifolius inhibit Staphylococcus aureus biofilm formation and improve response to antibiotics. PLoS One 7:e28737. doi: 10.1371/journal.pone.0028737

Raad, I. I., Fang, X., Keutgen, X. M., Jiang, Y., Sherertz, R., and Hachem, R. (2008). The role of chelators in preventing biofilm formation and catheterrelated bloodstream infections. Curr. Opin. Infect. Dis. 21, 385-392. doi: 10. 1097/QCO.0b013e32830634d8

Ramalingam, R., Dhand, C., Leung, C. M., Ong, S. T., Annamalai, S. K., Kamruddin, M., et al. (2019). Antimicrobial properties and biocompatibility of electrospun poly- $\varepsilon$-caprolactone fibrous mats containing Gymnema sylvestre leaf extract. Mater. Sci. Eng. C Mater. Biol. Appl. 98, 503-514. doi: 10.1016/j. msec.2018.12.135

Rendueles, O., Kaplan, J. B., and Ghigo, J. M. (2013). Antibiofilm polysaccharides. Environ. Microbiol. 15, 334-346. doi: 10.1111/j.1462-2920.2012.02810.x

Rogers, S. A., Huigens, R. W. III, Cavanagh, J., and Melander, C. (2010). Synergistic effects between conventional antibiotics and 2-aminoimidazolederived antibiofilm agents. Antimicrob. Agents Chemother. 54, 2112-2118. doi: 10.1128/AAC.01418-09

Romling, U., Galperin, M. Y., and Gomelsky, M. (2013). Cyclic di-GMP: the first 25 years of a universal bacterial second messenger. Microbiol. Mol. Biol. Rev. 77, 1-52. doi: 10.1128/MMBR.00043-12

Santos, R., Gomes, D., Macedo, H., Barros, D., Tibéro, C., Veiga, A. S., et al. (2016). Guar gum as a new antimicrobial peptide delivery system against diabetic foot ulcers Staphylococcus aureus isolates. J. Med. Microbiol. 65, 1092-1099. doi: 10.1099/jmm.0.000329

Schwartz, J. A., Lantis, J. C. II, Gendics, C., Fuller, A. M., Payne, W., and Ochs, D. (2013). A prospective, non comparative, multicenter study to investigate the effect of cadexomer iodine on bioburden load and other wound characteristics in diabetic foot ulcers. Int. Wound J. 10, 193-199. doi: 10.1111/j.1742-481X. 2012.01109.x

Seyed Ahmadi, S. G., Farahpour, M. R., and Hamishehkar, H. (2019). Topical application of Cinnamon verum essential oil accelerates infected wound healing process by increasing tissue antioxidant capacity and keratin biosynthesis. Kaohsiung J. Med. Sci. 35, 686-694. doi: 10.1002/kjm2.1 2120

Sharma, D., Misba, L., and Khan, A. U. (2019). Antibiotics versus biofilm: an emerging battleground in microbial communities. Antimicrob. Resist. Infect. Control. 8:76. doi: 10.1186/s13756-019-0533-3

Sharma, K., and Pagedar Singh, A. (2018). Antibiofilm effect of DNase against single and mixed species biofilm. Foods 7:E42. doi: 10.3390/foods703 0042

Sheldon, A. T. (2005). Antiseptic "Resistance": real or perceived threat? Clin. Infect. Dis. 40, 1650-1656. doi: 10.1086/430063

Singh, S., Singh, S. K., Chowdhury, I., and Singh, R. (2017). Understanding the Mechanism of Bacterial Biofilms Resistance to Antimicrobial Agents. Open Microbiol. J. 11, 53-62. doi: 10.2174/1874285801711010053

Snyder, R. J., Bohn, G., Hanft, J., Harkless, L., Kim, P., Lavery, L., et al. (2017). Wound Biofilm: current Perspectives and Strategies on Biofilm Disruption and Treatments. Wounds 29, S1-S17.

Stewart, P. S. (2015). Antimicrobial tolerance in biofilms. Microbiol. Spectr. 3, 10.1128/microbiolspec.MB-0010-2014. doi: 10.1128/microbiolspec.MB-00102014

Sully, E. K., Malachowa, N., Elmore, B. O., Alexander, S. M., Femling, J. K., Gray, B. M., et al. (2014). Selective chemical inhibition of agr quorum sensing in Staphylococcus aureus promotes host defense with minimal impact on resistance. PLoS Pathog. 10:e1004174. doi: 10.1371/journal.ppat.100 4174

Sun, H., Lv, H., Qiu, F., Sun, D., Gao, Y., Chen, N., et al. (2018). Clinical application of a 3D-printed scaffold in chronic wound treatment: a case series. J. Wound Care 27, 262-271. doi: 10.12968/jowc.2018.27.5.262

Taha, O. A., Connerton, P. L., Connerton, I. F., and El-Shibiny, A. (2018). Bacteriophage ZCKP1: a potential treatment for Klebsiella pneumoniae isolated from diabetic foot patients. Front. Microbiol. 9:2127. doi: 10.3389/fmicb.2018. 02127

Tan, D., Dahl, A., and Middelboe, M. (2015). Vibriophages Differentially Influence Biofilm Formation by Vibrio anguillarum Strains. Appl. Environ. Microbiol. 81, 4489-4497. doi: 10.1128/AEM.00518-15

Tardivo, J. P., Adami, F., Correa, J. A., Pinhal, M. A., and Baptista, M. S. (2014). A clinical trial testing the efficacy of PDT in preventing amputation in diabetic patients. Photodiagnosis Photodyn. Ther. 11, 342-350. doi: 10.1016/j.pdpdt. 2014.04.007

Tarusha, L., Paoletti, S., Travan, A., and Marsich, E. (2018). Alginate membranes loaded with hyaluronic acid and silver nanoparticles to foster tissue healing and to control bacterial contamination of non-healing wounds. J. Mater. Sci. Mater. Med. 29:22. doi: 10.1007/s10856-018-6027-7

Thombare, N., Jha, U., Mishra, S., and Siddiqui, M. Z. (2016). Guar gum as a promising starting material for diverse applications: a review. Int. J. Biol. Macromol. 88, 361-372. doi: 10.1016/j.ijbiomac.2016.04.001

Touzel, R. E., Sutton, J. M., and Wand, M. E. (2016). Establishment of a multispecies biofilm model to evaluate chlorhexidine efficacy. J. Hosp. Infect. 92, 154-160. doi: 10.1016/j.jhin.2015.09.013

Townsend, E. M., Sherry, L., Rajendran, R., Hansom, D., Butcher, J., MacKay, W. G., et al. (2016). Development and characterisation of a novel threedimensional inter-kingdom wound biofilm model. Biofouling 32, 1259-1270. doi: 10.1080/08927014.2016.1252337

Uçkay, I., Kressmann, B., Malacarne, S., Tournanova, A., Jaafar, J., Lew, D., et al. (2018). A randomized, controlled study to investigate the efficacy and safety of a topical gentamicin-collagen sponge in combination with systemic antibiotic therapy in diabetic patients with a moderate or severe foot ulcer infection. BMC Infect. Dis. 18:361. doi: 10.1186/s12879-018-3253-z

Vågesjö, E., Öhnstedt, E., Mortier, A., Lofton, H., Huss, F., Proost, P., et al. (2018). Accelerated wound healing in mice by on-site production and delivery of CXCL12 by transformed lactic acid bacteria. Proc. Natl. Acad. Sci. U. S. A. 115, 1895-1900. doi: 10.1073/pnas.1716580115

Vuotto, C., Longo, F., and Donelli, G. (2014). Probiotics to counteract biofilmassociated infections: promising and conflicting data. Int. J. Oral Sci. 6, 189-194. doi: 10.1038/ijos.2014.52

Walker, M., Metcalf, D., Parsons, D., and Bowler, P. (2015). A real-life clinical evaluation of a next-generation antimicrobial dressing on acute and chronic wounds. J. Wound Care 24, 11-22. doi: 10.12968/jowc.2015. 24.1 .11 
Willcox, M. D. P., Hume, E. B. H., Aliwarga, Y., Kumar, N., and Cole, N. (2008). A novel cationic-peptide coating for the prevention of microbial colonization on contact lenses. J. Appl. Microbiol. 105, 1817-1825. doi: 10.1111/j.1365-2672. 2008.03942.x

Wolcott, R. D., Kennedy, J. P., and Dowd, S. E. (2009). Regular debridement is the main tool for maintaining a healthy wound bed in most chronic wounds. J. Wound Care 18, 54-56.

Wu, H., Moser, C., Wang, H. Z., Høiby, N., and Song, Z. J. (2015). Strategies for combating bacterial biofilm infections. Int. J. Oral Sci. 7, 1-7. doi: 10.1038/ijos. 2014.65

Wu, S. C., Driver, V. R., Wrobel, J. S., and Armstrong, D. G. (2007). Foot ulcers in the diabetic patient, prevention and treatment. Vasc. Health Risk Manag. 3, 65-76.

Wukich, D. K., Dikis, J. W., Monaco, S. J., Strannigan, K., Suder, N. C., and Rosario, B. L. (2015). Topically applied vancomycin powder reduces the rate of surgical site infection in diabetic patients undergoing foot and ankle surgery. Foot Ankle Int. 36, 1017-1024. doi: 10.1177/1071100715586567

Yang, Q., Larose, C., Della Porta, A. C., Schultz, G. S., and Gibson, D. J. (2017). A surfactant-based wound dressing can reduce bacterial biofilms in a porcine skin explant model. Int. Wound J. 14, 408-413. doi: 10.1111/iwj.12619
Conflict of Interest: CP is the recipient of a grant from Biofilm Control (Bourse CIFRE).

The remaining authors declare that the research was conducted in the absence of any commercial or financial relationships that could be construed as a potential conflict of interest.

Publisher's Note: All claims expressed in this article are solely those of the authors and do not necessarily represent those of their affiliated organizations, or those of the publisher, the editors and the reviewers. Any product that may be evaluated in this article, or claim that may be made by its manufacturer, is not guaranteed or endorsed by the publisher.

Copyright $\odot 2021$ Pouget, Dunyach-Remy, Pantel, Boutet-Dubois, Schuldiner, Sotto, Lavigne and Loubet. This is an open-access article distributed under the terms of the Creative Commons Attribution License (CC BY). The use, distribution or reproduction in other forums is permitted, provided the original author(s) and the copyright owner(s) are credited and that the original publication in this journal is cited, in accordance with accepted academic practice. No use, distribution or reproduction is permitted which does not comply with these terms. 